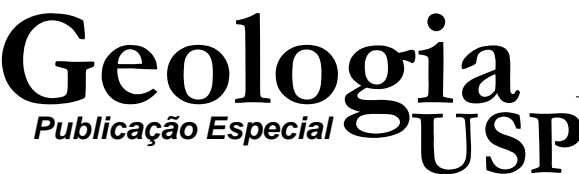

\section{O Currículo de Geologia em Face das Diretrizes Nacionais Curriculares e das Atribuições Profissionais}

\author{
Valdecir de Assis Janasi (vajanasi@usp.br) \\ Departamento de Mineralogia e Geotectônica - Instituto de Geociências - USP \\ R. do Lago 562, CEP 05508-080, São Paulo, SP, BRA
}

Recebido em 12 de dezembro de 2006; aceito em 12 de março de 2007

Palavras-chave: diretrizes curriculares, regulamentação profissional, Trabalho de Formatura.

\section{RESUMO}

Uma avaliação do currículo de Graduação em Geologia vigente na USP é feita à luz dos novos conceitos a ele incorporados, em comparação com o currículo anterior, com outros cursos de Geologia do Brasil e com cursos tradicionais da própria USP. Em comparação com a estrutura anterior, o curso sofreu uma redução importante na carga de aulas (23\%), principalmente em disciplinas básicas (36\%), e tornou-se mais flexível, com 25\% de sua carga horária correspondendo a disciplinas optativas (9\%) e ao Trabalho de Formatura (16\%). Considerando o contexto atual e projeções futuras do mercado de trabalho e da regulamentação profissional, sugere-se manter a proporção atual entre disciplinas básicas, geológicas e profissionalizantes, bem como a flexibilidade do currículo. Esta última, no entanto, poderia ser utilizada de modo mais efetivo com um redimensionamento do Trabalho de Formatura, e aumento da proporção de disciplinas optativas. Considera-se também fundamental que a comunidade geológica concentre esforços no sentido de aprovar, junto ao Conselho Federal de Educação, as Diretrizes Nacionais Curriculares, que constituem a base para a criação de novos cursos, reformas mais profundas de currículos atuais, e para o melhor entrosamento entre universidade e os órgãos de regulamentação profissional.

Keywords: curricular guidelines, professional regulation, Undergraduate Thesis.

\section{ABSTRACT}

An evaluation of the curriculum of the Batchelor in Geology degree at the University of São Paulo is presented in the light of the new concepts incorporated to it as compared to the previous curriculum, to other programs of undergraduate Geology in Brazil, and to other traditional programs in the same University. Compared to the previous structure, an important reduction in the number of class hours (23\%) occurred, especially in the fundamental courses (36\%); the program also became more flexible, with $25 \%$ of the total number of class hours corresponding to optional courses (9\%) and an Undergraduate Thesis (16\%). Taking into account the present situation and projections of the professional market, and also the new regulations for professional exercise, it is suggested that the current proportion between fundamental, geological and applied courses, as well as the flexibility of the program, are maintained. The flexibility, however, could be more effective by diminishing the number of hours of the Undergraduate Thesis, which could be occupied by a larger number of optional disciplines. It seems also important that the geological community concentrates its efforts to approve, at the Federal Education Council, the national curricular guidelines, which constitute the basis for the creation of new programs, for any more profound reformulations of current curricula, and for a better understanding between the universities and the professional regulation organisms. 


\section{INTRODUÇÃO}

O curso de Bacharelado em Geologia da USP foi fundado em 1957, dentro da antiga Faculdade de Filosofia, Ciências e Letras. É um dos mais tradicionais do Brasil e, ao longo de seus 50 anos que ora se completam, sempre foi reconhecido como um curso de excelência, no meio profissional e acadêmico, como atestado pelo papel de liderança que exercem seus egressos no mundo do trabalho e por avaliações independentes, como, por exemplo, o prêmio "Melhores Universidades do Brasil” instituído pela Editora Abril nos últimos anos.

É obrigação de um curso que pretende se manter numa posição de excelência a contínua avaliação de sua qualidade, lançando um olhar crítico sobre seu passado e pensando o futuro do profissional que nele se forma. É neste contexto que se realizou em outubro de 2006 o Seminário de Avaliação do Currículo do Bacharelado em Geologia da USP, 12 anos após a implantação do currículo atual.

Neste trabalho, apresentado como uma introdução ao seminário, propõe-se o exame desse currículo à luz dos seguintes parâmetros:

1. as diretrizes gerais para a educação superior brasileira, aprovadas cerca de três anos após a implantação desse currículo (Lei 9394 de 20/12/1996), e as Diretrizes Nacionais Curriculares (DNC) para os cursos de geologia, que existem na forma de uma proposta aprovada pelo Fórum Nacional de Coordenadores da SBG em 26/04/2002, mas que ainda não se encontram definidas no Conselho Federal de Educação do MEC;

2. a situação atual e as perspectivas profissionais do geólogo, tendo em conta as recentes alterações na regulamentação da atribuição de títulos profissionais, decorrentes da Resolução 1010 do CONFEA, aprovada em 22/08/2005 e que entrará em vigor em até 180 dias a partir do estabelecimento pelo CONFEA de critérios para padronização de procedimentos;

3. uma análise do currículo atual a partir da comparação com o currículo anterior, com o currículo de outros cursos de excelência: cursos de Geologia de outras universidades brasileiras, e cursos de graduação em outras áreas tradicionais dentro da Universidade de São Paulo.

\section{AS BASES PARA FORMULAÇÃO DO CURRÍCULO: LDB E DNC}

A Lei 9394 de 20/12/1996, que estabelece as diretrizes e bases da educação nacional, determina em seu Art. 43 as finalidades da educação superior no Brasil, destacando entre elas: "estimular a criação cultural e o desenvolvimento do espírito crítico e do pensamento reflexivo" e "formar diplomados nas diferentes áreas do conhecimento, aptos para a inserção em setores profissionais e para a participação no desenvolvimento da sociedade brasileira...”. O Art. 53 assegura às universidades, no exercício de sua autonomia, entre outras atribuições, a de "fixar os currículos de seus cursos e programas, observadas as diretrizes gerais pertinentes".

Desde a aprovação da Lei 9394, vêm sendo aprovadas junto ao Conselho Federal de Educação as Diretrizes Nacionais Curriculares de diversos cursos de graduação; entre aqueles aprovados recentemente podem ser citados a Biologia, a Agronomia e a Pedagogia, e entre aqueles ainda não aprovados pode-se citar a Geologia e a Arquitetura.

O esforço da comunidade geológica para aprovar suas Diretrizes Curriculares, uma salvaguarda fundamental para a profissão, tem sido intenso, e culminou com a aprovação de uma proposta pelo Fórum Nacional de Coordenadores de Curso, da Sociedade Brasileira de Geologia, em 26/04/2002, em Campinas - SP, que se encontra publicada na revista Terrae Didática (Nummer et al., 2005). É intenção expressa do Fórum que esta proposta substitua um documento prévio encaminhado ao Conselho Federal de Educação pelo próprio Fórum (Mesquita et al., 2001), que sintetizava sugestões de alteração de documento elaborado por uma Comissão de especialistas do Ensino de Geologia e Oceanografia designada pela Secretaria de Educação Superior do MEC. Até o momento, aparentemente, o processo encontra-se parado no Setor de Apoio Operacional do CNE, aguardando a designação de uma Comissão relatora (Nummer et al., 2005).

Em linhas gerais, o documento do Fórum propõe que os cursos de geologia devem formar um profissional "que tenha condição de trabalhar em qualquer área de atuação das Ciências Geológicas; interesse e capacidade para o trabalho de campo; visão abrangente das Geociências e de suas interações com ciências correlatas; pleno domínio da linguagem técnica geológica aliada à capacidade de adequação desta linguagem à comunicação com outros profissionais e com a Sociedade; conhecimento de ciências exatas que permita abordagens quantitativas das informações geológicas; e familiaridade com métodos e técnicas de informática, especialmente no tocante ao geoprocessamento". Para tanto, as diretrizes curriculares devem "privilegiar a capacidade de abordar e resolver problemas geológicos com competência, aliando uma sólida base teórica a um treinamento prático e intensivo". Além disto, o egresso deverá ter "atitude ética, autônoma, crítica, criativa, empreendedora e atuação propositiva, na busca de soluções de questões de interesse da sociedade”.

O conteúdo curricular deve contemplar a formação básica e profissional do geólogo. Além disso, conteúdos temáticos adicionais poderão ser estabelecidos de acordo 
com as competências ou objetivos existentes nas Instituições de Ensino e inseridas no contexto regional de cada uma delas.

Dividem-se, assim, os conteúdos em:
a. formação básica;
b. formação geológica específica;
c. formações temáticas.

estas últimas estabelecidas segundo as características e competências de cada Curso.

A formação básica, que deverá possuir caráter obrigatório, inclui conteúdos em Matemática, Estatística, Física, Computação, Química, Biologia e Geociências. O conteúdo para a formação geológica específica deverá também possuir caráter obrigatório e abranger tópicos considerados indispensáveis à formação do geólogo, tendo a seguinte composição: conteúdos em Mineralogia, Cristalografia, Topografia, Petrologia, Petrografia, Sedimentologia, Paleontologia, Geologia Estrutural, Geotectônica, Estratigrafia, Geoquímica, Geofísica, Geologia Histórica, Geologia do Brasil, Fotogeologia, Sensoriamento Remoto, Pedologia, Geomorfologia, Geologia Econômica, Prospecção, Mapeamento Geológico, Recursos Hídricos e Recursos Energéticos.

Os temas específicos terão um caráter optativo, podendo ser permitido ao aluno mesclar vários tópicos entre aqueles oferecidos por cada Curso.

Pretende-se, desta forma, dotar o aluno de uma formação polivalente e adequar as Instituições de Ensino a realidades e demandas regionais. Os conteúdos temáticos propostos são: Geoprocessamento, Recursos Minerais, Recursos Energéticos, Recursos Hídricos, Geologia de Engenharia, Geologia Ambiental, Geologia Regional, Geofísica Aplicada e Licenciatura em Geociências. Propõe-se ainda a possibilidade de oferecer ao aluno um conteúdo complementar, também de caráter optativo, especialmente em temas de Ciências Humanas, tais como: Economia, Filosofia da Ciência, Gestão, Administração e Comunicação.

Incluem-se ainda nas Diretrizes Curriculares que os cursos de Graduação em Geologia devem contemplar:

1. um Trabalho de Conclusão de Curso em temas de conteúdo geológico;

2. uma carga horária de atividades de campo, que pode ou não estar contida na carga horária de diferentes disciplinas, ocupando pelo menos $20 \%$ do total do curso (por exemplo, $600 \mathrm{~h}$ para um curso de $3.000 \mathrm{~h}$ );

3. um estágio profissional supervisionado com 120 a $160 \mathrm{~h}$.

É de conhecimento geral que a maior parte dos cursos de Geologia do Brasil segue, em linhas gerais, essas dire- trizes; uma vez aprovadas seriam, contudo, necessárias adequações em alguns dos currículos para atender a demandas específicas como a existência de um Trabalho de Conclusão, a carga horária mínima de atividades de campo etc. No caso do curso da USP, como se verá a seguir, essas demandas são todas atendidas no currículo vigente, com a exceção do Estágio Supervisionado. No caso de novos cursos que estão sendo criados, contudo, existe uma grande preocupação na comunidade, reiteradamente destacada em reuniões recentes do Fórum Nacional de Coordenadores, de que a ausência de Diretrizes Nacionais Curriculares aprovadas pelo MEC resulte na implantação de currículos que não obedeçam a esses parâmetros mínimos de qualidade.

\section{O CURRÍCULO DO BACHARELADO EM GEOLOGIA DA USP}

\section{Características Gerais}

A Tabela 1 apresenta a Seqüência Aconselhada de Disciplinas Obrigatórias para o Bacharelado em Geologia da USP vigente a partir de 2007. O curso tem um total de 4.560 h (3.780 h totalizando 252 créditos-aula, e 780 h em 26 créditos-trabalho [pelo Regimento Geral da USP, cada crédito-aula corresponde a 15 h, e cada crédito-trabalho, que corresponde a atividades realizadas de forma independente do aluno, sem supervisão direta do professor, corresponde a $30 \mathrm{hl}$ ). As atividades do curso se distribuem em 36 disciplinas obrigatórias, que totalizam 3.360 h; estão previstos ainda um Trabalho de Formatura, que ocupa todo o último ano do curso, com 720 h (das quais 60 horas-aula e 660 h correspondentes a 22 créditostrabalho) e $420 \mathrm{~h}$ em disciplinas optativas livres, que correspondem, por exemplo, a 7 disciplinas com $60 \mathrm{~h}$ (ou 4 créditos-aula).

Algumas modificações foram introduzidas ao longo dos 12 anos de vigência do currículo; a mais recente, que passa a vigorar em 2007, foi feita com o objetivo de incorporar horas de aulas de campo previamente não contabilizadas em disciplinas como Geologia Estrutural, Geologia Histórica e do Brasil, Prospecção Mineral e Geologia Econômica, ou para contabilizar como tal atividades até então consideradas como créditos-trabalho (e não como aulas) nas duas disciplinas de Mapeamento. Como resultado, ocorreu um aumento de $1 \%$ do total de horas do curso (de 4.515 para $4.560 \mathrm{~h}$ ); a principal mudança se deu no aumento da proporção entre créditos-aula e créditos-trabalho (3.555 + 960 h, ou 3,7 para 1 na estrutura de 2006, e 4,8 para 1 na atual). $O$ total de horas de campo até 2006 contabilizava 420 h de aula, e a partir de 2007 a carga real, de $660 \mathrm{~h}$, foi corretamente incorporada ao currículo. 
Tabela 1. Bacharelado em Geologia - Disciplinas Obrigatórias (Seqüência Aconselhada) - a partir de 2007. Foi utilizada para comparação a estrutura vigente no ano de 1990, conforme consta do Boletim de Informações distribuído para os alunos naquele ano. CA = crédito-aula; $\mathbf{C T}=$ crédito-trabalho; $\mathbf{H}=$ hora; $\mathbf{T r a b}=$ trabalho; Teo $=$ teórica; Prat1 = prática; Plab = prática de laboratório; Pcam = prática de campo. Tipo de aula: $\mathbf{B G}=$ básica geológica; Bas = básica; $\mathbf{G e o}=$ geológica fundamental; Prof $=$ profissionalizante.

\begin{tabular}{|c|c|c|c|c|c|c|c|c|c|c|c|}
\hline Código & Nome & Sem & Tipo & CA & CT & H Aula & H Trab & Teo & Prat1 & Plab & Pcam \\
\hline $044-0100$ & Geologia Geral - Sistema Terra & $1+2$ & BG & 12 & 1 & 180 & 30 & 4 & 4 & & 0 \\
\hline $\mathrm{BIO0103}$ & Biologia & 1 & Bas & 4 & 0 & 60 & & 4 & & & \\
\hline MAE0116 & Noções de Estatística & 1 & Bas & 4 & 0 & 60 & & 4 & & & \\
\hline MAT0142 & Cálculo I para Geociências & 1 & Bas & 6 & 0 & 90 & & 6 & & & \\
\hline QFL0605 & Química Geral & 1 & Bas & 6 & 0 & 90 & & 6 & & & \\
\hline FAP0192 & Mecânica para Geociências & 2 & Bas & 6 & 0 & 90 & & 6 & & & \\
\hline GMG0106 & Cristalografia Fundamental & 2 & Geo & 4 & 0 & 60 & & 2 & 2 & & \\
\hline MAC0115 & Introdução à Computação para Ciências Exatas e Tecnologia & 2 & Bas & 4 & 0 & 60 & & 4 & & & \\
\hline MAT0152 & Cálculo II para Geociências & 2 & Bas & 4 & 0 & 60 & & 4 & & & \\
\hline QFL0404 & Físico - Química IV & 2 & Bas & 4 & 0 & 60 & & 4 & & & \\
\hline 044-0200 & Sensoriamento Remoto e Fotogeologia & $3+4$ & Geo & 6 & 0 & 90 & & 3 & & 3 & \\
\hline $044-0220$ & Geoquímica & 3 & Geo & 4 & 0 & 60 & & 2 & 2 & & \\
\hline FAP0291 & Eletromagnetismo para Geociências & 3 & Bas & 6 & 0 & 90 & & 4 & & 2 & \\
\hline GMG0220 & Mineralogia & $3+4$ & Geo & 8 & 0 & 120 & & 4 & & 4 & \\
\hline GSA0240 & Paleontologia & $3+4$ & Geo & 6 & 0 & 90 & & 3 & & 1,5 & 0 \\
\hline MAP0125 & Cálculo Numérico para Geociências & 3 & Bas & 4 & 0 & 60 & & 4 & & & \\
\hline FGE0294 & Fenômenos Ondulatórios para Geociências & 4 & Bas & 4 & 0 & 60 & & 4 & & & \\
\hline FLG0602 & Geomorfologia & 4 & Geo & 4 & 0 & 60 & & 4 & & & \\
\hline GSA0252 & Sedimentologia & 4 & Geo & 8 & 0 & 120 & & 4 & & 2 & 0 \\
\hline PCC2110 & Desenho para Geologia & 4 & & 2 & 0 & 30 & & 2 & & & \\
\hline PTR0201 & Topografia Geral & 4 & & 4 & 0 & 60 & & 4 & & & \\
\hline $0440-310$ & Mapeamento Sedimentar & $5+6$ & Geo & 7 & 1 & 105 & 30 & 1 & & 1 & 5 \\
\hline GMG0330 & Geologia Estrutural & $5+6$ & Geo & 12 & 0 & 180 & & 4 & 4 & & 0 \\
\hline GMG0331 & Petrologia Ígnea & 5 & Geo & 10 & 0 & 150 & & 2 & & 4 & 0 \\
\hline GSA0301 & Recursos Energéticos & 5 & Prof & 2 & 0 & 30 & & 2 & & & \\
\hline GSA0307 & Estratigrafia & 5 & Geo & 6 & 0 & 90 & & 2 & 3 & & 0 \\
\hline GMG0332 & Petrologia Metamórfica & 6 & Geo & 10 & 0 & 150 & & 2 & & 4 & 0 \\
\hline GSA0308 & Geofísica Aplicada & 6 & Prof & 4 & 0 & 60 & & 2 & 1 & & 0 \\
\hline GSA0312 & Hidrogeologia e Recursos Hídricos & 6 & Prof & 4 & 0 & 60 & & 2 & 1,5 & & 0 \\
\hline PEF0514 & Elementos de Geomecânica & 6 & Prof & 4 & 0 & 60 & & 4 & & & \\
\hline $0440-400$ & Geologia Histórica e do Brasil & $7+8$ & Geo & 12 & 0 & 180 & & 4 & 4 & & 4 \\
\hline 044-0419 & Gênese de Depósitos Minerais & 7 & Geo & 5 & 0 & 75 & & 3 & 1 & & 0 \\
\hline 044-0420 & Mapeamento Geológico & $7+8$ & Geo & 14 & 2 & 210 & 60 & 2 & & 2 & 10 \\
\hline GSA0400 & Prospecção, Pesquisa e Avaliação de Jazidas & $7+8$ & Prof & 10 & 0 & 150 & & 4 & 4 & & 2 \\
\hline PMI2735 & Geologia de Engenharia I & 7 & Prof & 6 & 0 & 90 & & 6 & & & \\
\hline GSA0418 & Geologia Econômica & 8 & Prof & 4 & 0 & 60 & & 2 & 2 & & \\
\hline \multirow[t]{4}{*}{$044-500$} & Trabalho de Formatura & $9+10$ & $\mathrm{TF}$ & 4 & 22 & 60 & 660 & & 4 & & \\
\hline & Optativas & & Opt & 28 & 0 & 420 & & & & & \\
\hline & Total-créditos & & & 252 & 26 & & & 124 & 28,5 & 23,5 & 21 \\
\hline & Total-horas & & & 3.780 & 780 & 3.300 & 120 & 1.860 & 427,5 & 352,5 & 315 \\
\hline
\end{tabular}

\section{Comparação com o currículo antigo (até 1993)}

Uma série de novidades foi introduzida no currículo vigente a partir de 1994, das quais as mais importantes foram:

1. a existência de disciplinas anuais, muitas das quais constituintes da "espinha dorsal" do curso;

2. a existência de disciplinas interdepartamentais, que correspondem à maior proporção da carga total de disciplinas oferecidas pelo Instituto de Geociências ao curso;

3. a criação de uma disciplina introdutória única, interde- partamental e anual, intitulada “Geologia Geral- Sistema Terra”;

4. a criação do Trabalho de Formatura, com regulamento próprio, planejado para ocupar o último ano do curso, e com elevada carga horária (720 h);

5. a criação de “Opções de concentração”, que permitiriam ao aluno direcionar sua formação para uma "especialização precoce” através de um conjunto de disciplinas optativas e da temática do seu Trabalho de Formatura;

6. a organização dos trabalhos de campo, que seriam distribuídos ao longo do curso em grau crescente de dificuldade, contexto no qual foi criada a disciplina Mapeamento Sedimentar, que precederia o Mapeamento Geológico. 
Outro objetivo importante da mudança curricular foi a diminuição do número total de disciplinas, por se entender que o currículo deveria ser mais compacto, e a diminuição do número total de horas de aula, considerado muito elevado.

A comparação com o currículo antigo, apresentada na Figura 1 mostra que de fato ocorreu no currículo vigente uma significativa diminuição das horas de aula efetivamente ministradas, de $1.140 \mathrm{~h}$, ou 22,9\%, tendo em vista que do total de horas daquela estrutura $(4.980 \mathrm{~h})$, apenas $60 \mathrm{~h}$ da disciplina Mapeamento Geológico correspondiam a créditos-trabalho. As demais 540 h contabilizadas como "créditos-trabalho" correspondiam a aulas de campo, e não a atividades independentes do aluno, o que foi corrigido na elaboração do currículo vigente, mas em alguns casos (como na disciplina optativa Geotectônica), foi mantido e só corrigido nas mudanças curriculares aprovadas para 2007. A diminuição mais drástica foi feita para as disciplinas básicas (450 h, ou 36,5\%); como testemunhado pelos alunos durante o presente Seminário de Avaliação, esta diminuição parece ter resultado na compactação exagerada e agrupamento pouco adequado de programas em pelo menos um caso: o conteúdo de Geometria Analítica alocado nas disciplinas de Cálculo.

Em termos de distribuição das várias modalidades de aula, a principal delas foi a introdução das $720 \mathrm{~h}$ (das quais, contudo, apenas $60 \mathrm{~h}$ correspondem a horas-aula) da disciplina Trabalho de Formatura. Observa-se na Figura 1 que os $16 \%$ da carga horária total do currículo vigente ocupados por esta disciplina resultaram na diminuição da proporção ocupada pelas disciplinas básicas (-8\%), geológicas (-4\%) e profissionalizantes (-3\%).

\section{Comparação com outros cursos de Geologia do Brasil}

A Figura 2 apresenta uma comparação com outros cursos de geologia de referência brasileiros. O curso da UNESPRio Claro (ora em processo de reforma curricular), que tem o mesmo total de horas totais que o da USP (4.560 h), é o menos flexível (6\% na soma de Trabalho de Formatura e disciplinas optativas) e, por larga margem, é aquele que tem maior carga de disciplinas profissionalizantes (26\% contra 11 - 14\% nos demais). Os cursos da UNB e da UFRJ, que totalizam em torno de 4.000 h, mostram também suas especificidades: o primeiro não tem Trabalho de Formatura, o que é compensado com a maior proporção de horas em disciplinas optativas (18\%); o curso da UFRJ tem a maior proporção de disciplinas geológicas (56\%, para as quais contribui uma forte carga de horas de aulas de campo), e a menor de disciplinas básicas não geológicas (15\%). No curso da USP as proporções de disciplinas geológicas e profissionalizantes são um pouco menores que nos demais; no entanto trata-se do curso com maior flexibilidade curricular, pois a soma de Trabalho de Formatura e disciplinas optativas corresponde a $25 \%$ do total de horas, permitindo, por exemplo, que o aluno ocupe até $36 \%$ de sua carga horária com conteúdos profissionalizantes ou $65 \%$ com conteúdos geológicos básicos. O Trabalho de Formatura do curso da USP é, por larga margem, aquele com maior carga horária dentro do conjunto, e também em relação aos demais cursos do Brasil.

\section{Comparação com outros cursos da USP}

A comparação com outros cursos da USP, muitos deles reconhecidos como os melhores do Brasil em suas áreas, é um importante parâmetro de avaliação de excelência. A Tabela 2 mostra esta comparação, baseada nos dados disponíveis no Sistema Júpiter para os currículos vigentes no ano de 2007, destacando os seguintes parâmetros:

a. proporção de horas totais por ano;

b. proporção de horas de aula efetivamente ministradas;

c. proporção de horas correspondentes aos créditostrabalho;

d. grau de flexibilidade do currículo (proporção de horas optativas);

e. Trabalho de Formatura.

O número de horas aula/ano varia bastante entre os cursos da USP, desde casos como Economia, Geofísica e Direito, com menos de $800 \mathrm{~h}$ aula/ano, até os de cursos da área de saúde, como Medicina, Odontologia, Psicologia, Farmácia-Bioquímica e Fonoaudiologia (mas incluindo também a Arquitetura), com cargas superiores a $1.000 \mathrm{~h}$ aula/ano. $\mathrm{O}$ curso de Geologia, com 912 h aula/ano, situa-se na porção inferior de um bloco intermediário (com totais entre 900 e $1.000 \mathrm{~h}$ aula/ano), no qual se incluem cursos afins como a Engenharia de Minas, Engenharia do Petróleo, Engenharia Ambiental e Oceanografia, e cursos tradicionais, como Química e Administração.

Consideradas as horas de aula efetivamente ministradas (excluindo, portanto, atividades exclusivas dos alunos, ou créditos-trabalho), a Geologia, com 3.780 h (a partir de 2007; 3.555 h em 2006) só tem número superior ao de Geofísica e Oceanografia entre os cursos com duração de 5 anos. Em comparação, as Engenharias têm totais muito parecidos, variando entre 3.825 e $4.020 \mathrm{~h}$.

A proporção comparativamente mais baixa de horas de aula se deve, evidentemente, a uma elevada proporção de créditos-trabalho, critério pelo qual o curso de Geologia se situava, até 2006, no bloco dos cursos com maior proporção, sendo superado, entre os cursos comparados, apenas por Geografia, Geofísica, Oceanografia, Psicologia e Medi- 
(A) Horas-aula por tipo de disciplina

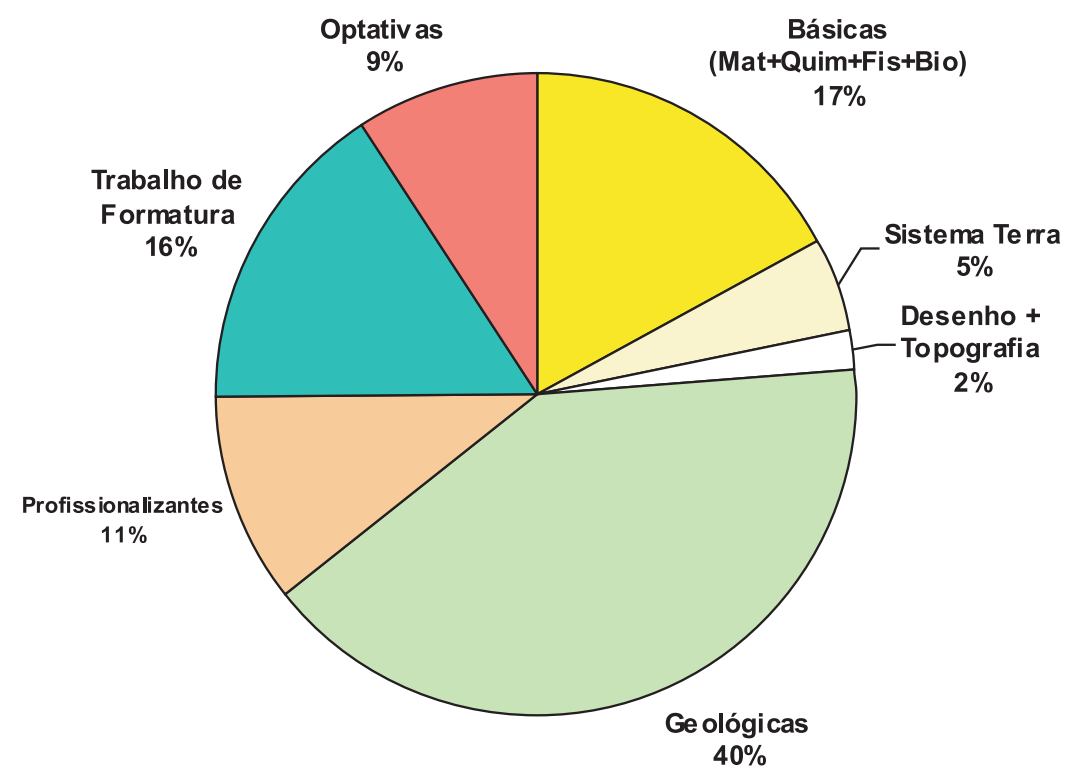

(B) Geologia USP - Currículo até 1993

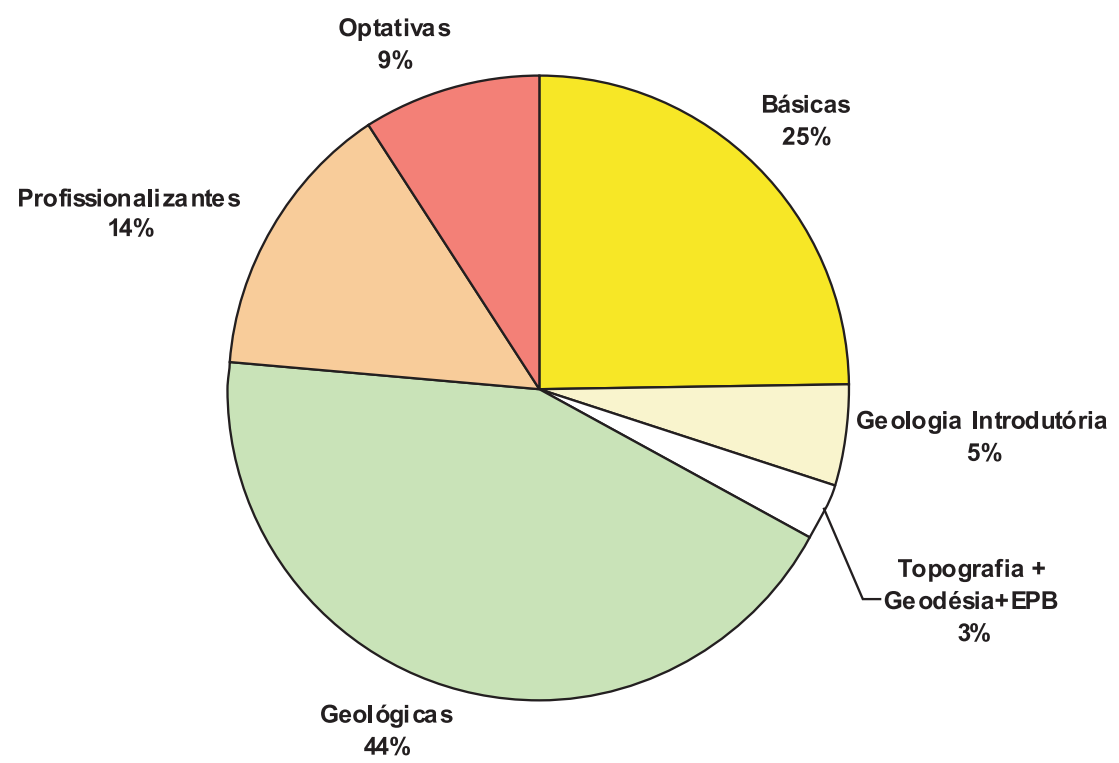

Figura 1. Comparação entre a proporção de horas-aula do currículo atual (A) e antigo (até 1993, B), divididas por tipo de disciplinas. As disciplinas básicas foram divididas em Geologia Introdutória (ou Sistema Terra) e outras (Matemática, Física, Química e Biologia). Algumas disciplinas, como Desenho, Topografia e Estudo de Problemas Brasileiros, não se enquadram claramente nas categorias aqui definidas, e foram consideradas em separado. A divisão entre disciplinas "Geológicas" e "Profissionalizantes" tem alguma carga de subjetividade; o critério aqui adotado é ilustrado pela divisão feita na Tabela 1. 

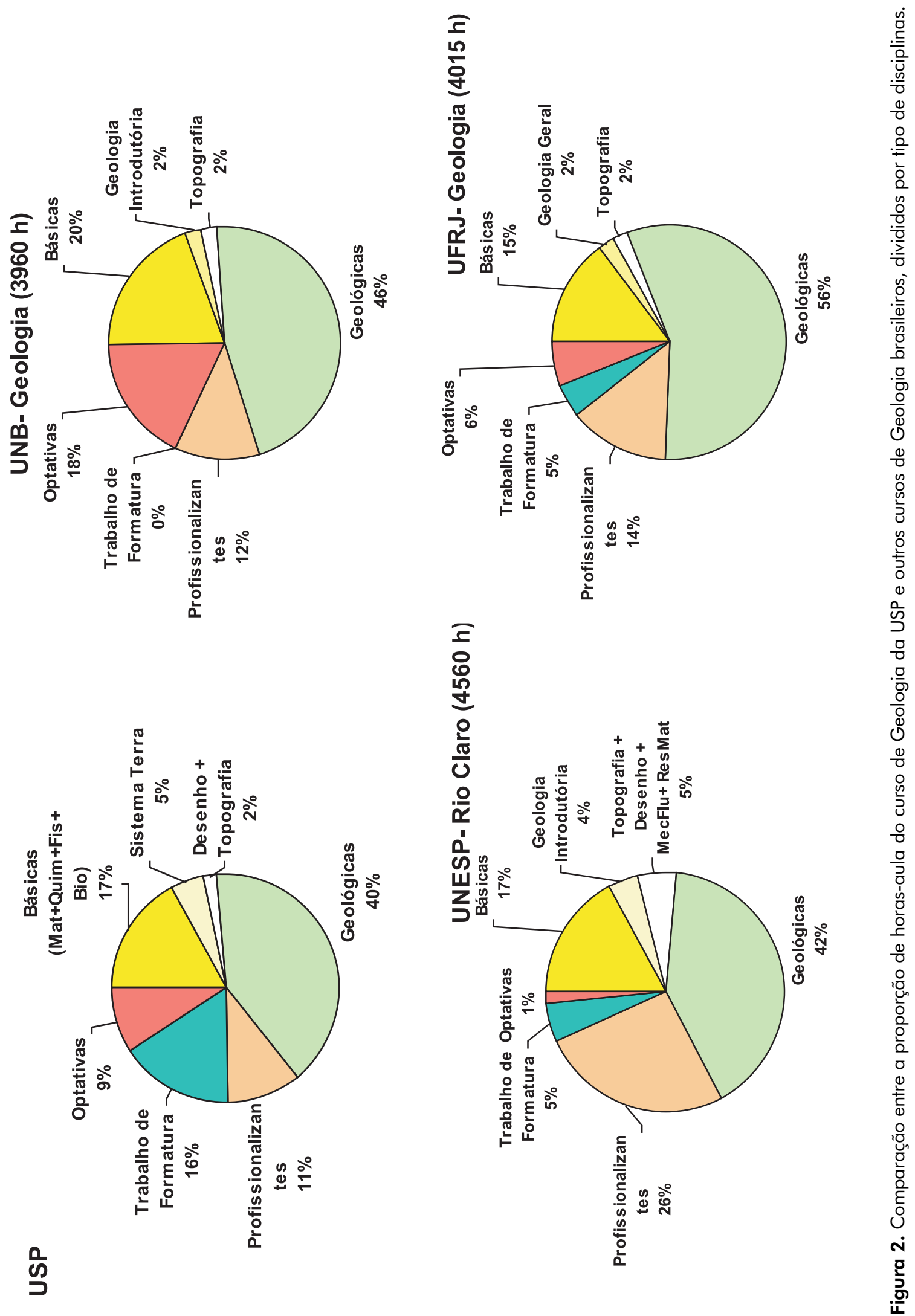
Tabela 2. Comparação entre a distribuição de atividades em estruturas curriculares de alguns cursos de graduação da USP. Estruturas curriculares segundo o Sistema Júpiter-USP, vigentes em 01/01/2007. Cursos ordenados em horas/ano crescente. Colunas: \% Trabalho, \% Optativas e \% Opt. + TF correspondem, respectivamente, às porcentagens de horastrabalho, de horas em disciplinas optativas, e de horas em optativas + Trabalho de Formatura. ${ }^{*}=$ Estágio não obrigatório; nos demais casos, quando assinalado, estágio obrigatório.

\begin{tabular}{|c|c|c|c|c|c|c|c|c|c|c|c|c|c|}
\hline Curso & Anos & $\begin{array}{l}\text { Horas/ } \\
\text { aula }\end{array}$ & $\begin{array}{l}\text { Obrigatórias } \\
\text { (horas) }\end{array}$ & $\begin{array}{c}\text { Opt. } \\
\text { Eletiva } \\
\text { (horas) }\end{array}$ & $\begin{array}{c}\text { Opt. } \\
\text { Livre } \\
\text { (horas) }\end{array}$ & $\begin{array}{c}\text { Trabalho } \\
\text { (horas) }\end{array}$ & $\begin{array}{c}\text { Total } \\
\text { (horas) }\end{array}$ & $\begin{array}{l}\text { TF/TCC } \\
\text { (horas) }\end{array}$ & $\begin{array}{l}\text { Estágio } \\
\text { (horas) }\end{array}$ & $\begin{array}{c}\text { Horas/ } \\
\text { ano }\end{array}$ & $\begin{array}{c}\% \\
\text { Trabalho }\end{array}$ & $\begin{array}{c}\% \\
\text { Optativas }\end{array}$ & $\begin{array}{c}\% \\
\text { Opt+TF }\end{array}$ \\
\hline Economia & 4 & 2.760 & 1.500 & 840 & 420 & & 2.760 & 390 & - & 690 & 0,0 & 45,7 & 59,8 \\
\hline Geofísica & 5 & 2.880 & 2.400 & 300 & 180 & 780 & 3.660 & 870 & - & 732 & 21,3 & 13,1 & 36,9 \\
\hline Direito & 5 & 3.795 & 3.195 & 600 & & 60 & 3.855 & 0 & - & 771 & 1,6 & 15,6 & 15,6 \\
\hline Agronomia & 5 & 4.170 & 3.060 & 1.110 & & 60 & 4.230 & 0 & $105^{*}$ & 846 & 1,4 & 26,2 & 26,2 \\
\hline Biologia & 4 & 2.955 & 2.955 & & & 450 & 3.405 & 240 & - & 851 & 13,2 & 0,0 & 7,0 \\
\hline Eng. Civil & 5 & 3.825 & 3.585 & 240 & & 270 & 4.095 & 120 & 180 & 855 & 6,6 & 5,9 & 8,8 \\
\hline Eng. Ambiental & 5 & 3.840 & 3.600 & 240 & & 660 & 4.500 & 120 & 150 & 900 & 14,7 & 5,3 & 8,0 \\
\hline Geologia & 5 & 3.780 & 3.360 & & 420 & 780 & 4.560 & 720 & - & 912 & 17,1 & 9,2 & 25,0 \\
\hline Geografia & 4 & 2.490 & 1.470 & 1.020 & & 1.200 & 3.690 & 600 & $120-150^{*}$ & 923 & 32,5 & 27,6 & 43,9 \\
\hline Eng. Minas & 5 & 4.020 & 4.020 & & & 600 & 4.620 & 150 & 195 & 924 & 13,0 & 0,0 & 3,2 \\
\hline Oceanografia & 5 & 3.450 & 3.000 & 300 & 150 & 1.020 & 4.470 & 540 & 150 & 924 & 22,8 & 10,1 & 22,1 \\
\hline Eng. Petróleo & 5 & 4.020 & 3.960 & 60 & & 660 & 4.680 & 150 & 390 & 936 & 14,1 & 1,3 & 4,5 \\
\hline Administração & 4 & 2.790 & 2.460 & 120 & 210 & 660 & 3.450 & 420 & 300 & 938 & 19,1 & 9,6 & 21,7 \\
\hline Química & 4 & 3.705 & 2.775 & 930 & & 150 & 3.855 & 0 & - & 964 & 3,9 & 24,1 & 24,1 \\
\hline Med. Veterinária & 5 & 4.590 & 4.560 & 30 & & 450 & 5.040 & 0 & 480 & 1.008 & 8,9 & 0,6 & 0,6 \\
\hline Psicologia & 4 & 2.760 & 2.190 & 30 & 540 & 1.530 & 4.290 & 240 & 360 & 1.073 & 35,7 & 13,3 & 18,9 \\
\hline Fonoaudiologia & 4 & 3.765 & 2.430 & 960 & 375 & 780 & 4.545 & 0 & 650 & 1.136 & 17,2 & 29,4 & 29,4 \\
\hline Arquitetura & 5 & 4.560 & 4.020 & 540 & & 1.170 & 5.730 & 240 & - & 1.146 & 20,4 & 9,4 & 13,6 \\
\hline Farmácia-Bioq & 5 & 4.125 & 3.615 & & 510 & 840 & 4.965 & 0 & 840 & 1.161 & 16,9 & 10,3 & 10,3 \\
\hline Odontologia & 4,5 & 5.070 & 5.070 & & & 720 & 5.790 & 0 & 480 & 1.287 & 12,4 & 0,0 & 0,0 \\
\hline Medicina & 6 & 7.560 & 7.140 & 420 & & 3.180 & 10.740 & 0 & 4.500 & 1.790 & 29,6 & 3,9 & 3,9 \\
\hline
\end{tabular}

cina, estes dois últimos devido às atividades de clínica e residência. A redistribuição de créditos de campo efetuada nas mudanças curriculares em 2007 modificou um pouco esta situação, diminuindo a proporção de créditos-trabalho no currículo da Geologia de 21,3\% para 17,1\%), e a aproximando do bloco de cursos com proporção intermediária de créditos-trabalho (10-15\% do total de horas), no qual se situa a maioria dos cursos de Engenharia. Em contrapartida, observa-se que créditos-trabalho ocupam proporção muito pequena dos currículos de alguns cursos da USP, como Direito, Economia e Agronomia.

Em termos de flexibilidade, as $420 \mathrm{~h}$ de disciplinas optativas do curso de geologia (correspondentes a 9,2\% do total) sugerem ser o curso pouco flexível, em especial se comparado a cursos como Química e Agronomia, nos quais o aluno ocupa com disciplinas optativas proporção superior a $20 \%$ do total de horas. Observa-se, também aqui, que diversos cursos da USP têm currículos com proporção ainda menor de disciplinas optativas, aí incluídas as Engenharias e a maioria dos cursos da área de saúde. Parece existir atualmente na USP uma tendência a maior flexibilização dos currículos, como mostra a nova estrutura curricular proposta para os cursos de Biologia, que prevê concentrar todas as disciplinas obrigatórias na primeira metade do curso, contra a situação atual, na qual não são previstas disciplinas optativas.

Uma medida mais adequada da flexibilidade da grade curricular de um curso, contudo, é a somatória das horas previstas para disciplinas optativas e para atividades como os Trabalhos de Formatura e Estágios Curriculares, cuja temática é também de livre escolha do aluno. Por este parâmetro, o curso de Geologia, com 25\%, está entre os mais flexíveis da USP, só sendo superado, entre os cursos pesquisados, por Fonoaudiologia, Agronomia, Geofísica, Geografia e Economia (cf. Tabela 2).

\section{O CURRÍCULO DO GEÓLOGO E AS ATRIBUIÇÕES PROFISSIONAIS}

O momento atual é notavelmente distinto daquele vivido quando da reforma que gerou o currículo atual do curso de Geologia da USP em 1994, e certamente mais favorável ao profissional geólogo. Concretizou-se no período uma importante expansão das áreas de atuação profissionais, com especial destaque para Geologia Ambiental e Hidrogeologia, enquanto as áreas tradicionais como Geologia do Petróleo, Prospecção de Minérios Metálicos e mesmo os Levantamentos Geológicos Básicos retomaram com vigor a deman- 
da pelo geólogo (cf. apresentações neste seminário de Juliani et al., Campos Neto et al. e R. Bertolo). Como resultado, as pressões mais evidentes que se observam atualmente no ambiente profissional são:

a. pela colocação de mais geólogos no mercado;

b. pela criação de novos cursos de geologia no país;

c. pela ocupação de áreas de atuação do geólogo por outros profissionais.

Nesse contexto, antes que modificações significativas na forma como o geólogo é formado, o momento parece demandar uma defesa da profissão, seja pela atuação junto a órgãos de regulamentação do exercício profissional, seja pela garantia da manutenção da qualidade do contingente adicional de geólogos que será gerado no futuro próximo, dentro dos cursos já estabelecidos ou naqueles que estão sendo criados [atualmente encontram-se em implantação quatro cursos de graduação em Geologia em universidades federais: UFPA, no campus de Marabá, com 30 vagas; UFES, no campus de Alegre, com 40 vagas; UFBA, no campus de Barreiras; UFSE, em Aracaju, com previsão de 50 vagas].

A Resolução 1010 do CONFEA, recentemente aprovada e que deverá se aplicar obrigatoriamente às novas turmas ingressantes a partir de 2008, altera significativamente a maneira como os profissionais da área de Engenharia, Agronomia, Arquitetura e Geologia terão definidas as suas atribuições. Deste modo, faz-se necessária uma avaliação cuidadosa sobre seu impacto na formação do geólogo. O parágrafo segundo do Art. 7 da Resolução 1010 diz que "a atribuição inicial de título profissional, atividades e competências decorrerá, rigorosamente, da análise do perfil profissional do diplomado, de seu currículo integralizado e do projeto pedagógico do curso regular, em consonância com as respectivas diretrizes curriculares nacionais”. Algumas conseqüências importantes podem ser daí extraídas.

Uma das mudanças mais significativas introduzidas pela Resolução 1010 é a flexibilização das atribuições profissionais, ou seja, cada profissional terá suas atribuições iniciais definidas a partir do conjunto de disciplinas cursado. Novas atribuições poderão ser agregadas posteriormente, ganhando portanto importância fundamental a formação pós-graduada (ou “continuada”), o que traz para as universidades públicas a obrigação de refletir sobre como atuar diante da forte demanda esperada para esse tipo de formação: que espaço ocupará esse tipo de atividade dentro das instituições de ensino? Que critérios nortearão o acesso de alunos a ela?

Outra decorrência importante, já sentida por outras áreas que compõem o Sistema CONFEA-CREA, é que as diretrizes nacionais curriculares, que constituem sistemas reguladores fundamentais dos projetos pedagógicos regulam, portanto, nos termos do parágrafo acima citado, também os perfis profissionais. Assim, a ausência de DNC aprovadas no MEC, observada para geólogos e arquitetos, constitui grave obstáculo a um diálogo melhor estruturado entre as universidades e os órgãos de regulamentação profissional.

Cabe ainda destacar que o geólogo conquistou, ao longo de mais de 40 anos de exercício profissional regulamentado (pela Lei Federal 4076 de 23/06/1962), uma ampla gama de demandas do mercado que certamente não pode ser totalmente contemplada dentro da estrutura dos cursos de graduação em geologia. Neste sentido, os cursos de geologia do Brasil são desafiados a oferecer aos seus alunos currículos suficientemente flexíveis, e com amplas opções de disciplinas profissionalizantes que atendam aos requerimentos para atribuições mais específicas, ao mesmo tempo em que precisam preservar o conteúdo fundamental de disciplinas de formação básica e geológica, que respondem pela identidade do profissional geólogo.

\section{CONCLUSÕES E SUGESTÕES}

A avaliação aqui apresentada permite alinhavar algumas conclusões gerais, que são seguidas de sugestões sobre o futuro do currículo do Bacharelado em Geologia da USP.

O currículo atual atende adequadamente às DNC aprovadas pelo Fórum Nacional de Coordenadores, com exceção da sugestão de que exista um Estágio Curricular Supervisionado. A inclusão de uma disciplina como esta, de caráter optativo, deve ser considerada, uma vez que disciplinaria e daria créditos àquilo que, na prática, já ocorre no curso.

O conceito geral de formar um profissional polivalente é atendido pelo currículo; na prática, a procura praticamente nula pelas “opções de concentração” introduzidas no currículo mostra que os alunos preferem o perfil mais geral ou, caso construam um currículo com ênfase em uma área, não vislumbram vantagens em registrá-la formalmente em seu diploma. Ambas as opções, a de priorizar uma formação geral sólida, e a de não se direcionar formalmente para uma especialização precoce, parecem bastante justificadas. As alterações na forma de atribuição de títulos, atividades e competências profissionais introduzidas pela Resolução 1010 do CONFEA reforçam esse tipo de opção, uma vez que esta será feita a partir do conteúdo das disciplinas, que serão a princípio consideradas individualmente, e não como conjuntos formalizados em “especializações”. Neste sentido, parece-nos que seria recomendável extinguir as opções de concentração, que demandam a manutenção de um elenco exagerado de disciplinas optativas, sobrecarregando a carga didática docente no IGc.

Uma das grandes virtudes do currículo atual é seu caráter flexível, em uma proporção (25\% da carga horária) que nos parece muito adequada, pois permite ao aluno direcionar sua formação para as suas áreas de interesse, comportando 
portanto tanto um viés fortemente profissionalizante (até $36 \%$ da carga total) como um viés acadêmico. Ocorre, no entanto, que a flexibilidade é fortemente centrada no Trabalho de Formatura (16\%), uma novidade importante introduzida no currículo atual que teve grande êxito em valorizar as diferentes vocações dos estudantes. A carga horária do Trabalho de Formatura é muito superior à dos demais cursos de geologia do país e à de cursos de graduação das mais diversas áreas dentro da USP (na maior parte dos casos, inferiores a 300 h). Além disto, de acordo com avaliações preliminares, poderá encontrar dificuldades para agregar atribuições profissionais no contexto da Resolução 1010 do CONFEA. Parece-nos, nesse sentido, conveniente proceder a um redimensionamento do Trabalho de Formatura, como aliás também é a visão de colegas que se envolveram de modo mais intenso na sua organização em anos recentes (cf. Szabó et al., neste volume). Uma redução à metade da carga atual de 720 h permitiria a inclusão de 360 h de disciplinas optativas, correspondendo a 6 disciplinas típicas de $4 \mathrm{~h}$ semanais $\%$ espaço que poderia ser muito bem aproveitado pelo aluno para agregar uma ampla gama de atribuições profissionais.

Por fim, mas neste caso, ainda mais importante: é necessário que a comunidade geológica retome o processo de encaminhamento e aprovação, no Conselho Nacional de Educação, das Diretrizes Nacionais Curriculares. Na falta das DNC, a profissão encontra-se em risco, à medida de que a alta demanda por geólogos estimula a criação de novos cursos, cujos currículos podem ser criados sem o balizamento de critérios mínimos de qualidade (convém lembrar que todos os currículos dos cursos existentes antes da Lei 9394 obedeciam a currículo mínimo aprovado pelo MEC, que não mais existe). As DNC constituem também um balizamento fundamental para o espaço de diálogo com os órgãos de regulamentação do exercício profissional, sem o qual pode ser dificultada a necessária convergência entre universidade e profissão, o que é especialmente preocupante diante das mudanças recentemente aprovadas pelo CONFEA. Além disto, o desejo de alguns cursos de proceder reformas curriculares mais profundas resulta refreado, uma vez que a aprovação de novas DNC potencialmente levaria à necessidade de revisar, pouco adiante, as próprias bases em que o currículo foi montado.

\section{REFERÊNCIAS BIBLIOGRÁFICAS}

JULIANI, C.; BETTENCOURT, J. S.; GARDA, G. M. 2006. A importância do setor mineral no "curriculum" do curso de Geologia. In: SEMINÁRIO DE AVALIAÇÃO DO CURRÍCULO DO BACHARELADO EM GEOLOGIA, 1., 2006, São Paulo. Anais... São Paulo: Instituto de Geociências/ USP, 2006.
MESQUITA, F. J. G.; ARTUR, A. C.; LAZZAROTTO, A.; MISI, A.; LEIPNITZ, B.; BARROS, C. E.; CARNEIRO, C. D. R.; TUBBS FILHO, D.; ASSIS, F. P.; ABREU, F. A. M.; SOBREIRA, F.; MOURA, M.A.; TOLEDO, M. C. M.; SOUZA, M. A. T. A. de; COSTA, R. D.; ZOUAIN, R. N. A.; MENEGAT, R.; NADALIN, R. J.; SANTOS, R. A. A. dos; VASCONCELOS S. M. S.; MARQUES T. M.; NERI, T. F. O.; DIAS, V. M.; SOUZA Z. S. de. Sugestões de alteração para a proposta de diretrizes curriculares para os cursos de graduação em geologia e engenharia geológica. Salvador: Inst. Geoc./UFBA, 2001. 9 p. (documento inédito, elaborado com base nas contribuições do I Seminário Nacional sobre Cursos de Graduação em Geologia, Salvador, 30.05 a 01.06.2001).

NUMMER, A. R. et al. Diretrizes curriculares para os cursos de graduação em geologia e engenharia geológica. Terrae Didática, v. 1, n. 1, p. 64-69, 2005.

SZABÓ, G. A. J.; GARDA, G. M.; MCREATH, I. O trabalho de formatura: forma ou conteúdo? In: SEMINÁRIO DE AVALIAÇÃO DO CURRÍCULO DO BACHARELADO EM GEOLOGIA, 1., 2006, São Paulo. Anais... São Paulo: Instituto de Geociências/USP, 2006. 